\title{
'A Gleaming and Glorious Star': Rethinking History in the Plurality-of-Worlds Debate
}

\author{
Ben Carver
}

\section{Introduction: other worlds}

In August 1835, the New York Sun published a serialized account of John Herschel's lunar discoveries, supposedly written by his assistant, 'Dr. Andrew Grant'. Herschel the younger had, the Sun claimed, developed 'a telescope of vast dimensions and an entirely new principle' which allowed him to examine the moon at a previously unknown magnification. There, the account continued, he was able to observe flora and fauna in tremendous detail, including the behaviour of human-like though unrefined creatures: 'We scientifically denominated them as Vespertilio-homo, or man-bat; and they are doubtless innocent and happy creatures, notwithstanding that some of their amusements would but ill comport with our terrestrial notions of decorum' (Figure 1). ${ }^{1}$ Subsequent observations revealed architecture, evidence of civilization and even religion, which invited interpretation and conjecture:

Had the devotees of these temples gone the way of all living, or were the latter merely historical monuments? What did the ingenious builders mean by the globe surrounded by flames? Did they by this record any past calamity of their world, or predict any future one of ours? ${ }^{2}$

The excited response of many readers of these articles has led to the six New York Sun articles' classification as a hoax, but Michael J. Crowe claims that Richard Adams Locke, their author, intended them to be parodic of the more fanciful turns of astronomical speculation. ${ }^{3}$ They certainly incorporate important aspects of the plurality-of-worlds debate in the nineteenth century; there is the issue of scopic power and with it the expectation that a new generation of telescope would reveal new levels of visual detail, perhaps providing evidence of civilization and history on other planets. The want of 'decorum' among the bat-men, here alarming a fastidious and imaginary astronomer for comic effect, reflects anxieties about the propriety of even imagining alternate forms of life on other planets - a problem that intensified as one considered the possibility of human-like beings and their higher faculties. The lunar

1. Richard Adams Locke, The Moon Hoax: Or, A Discovery That the Moon has a Vast Population of Human Beings (New York: William Gowans, 1859), p. 38.

2. Locke, Moon Hoax, p. 44.

3. Michael J. Crowe, The Extraterrestrial Life Debate, 1750-1900 (Mineola, NY: Dover, 1999), p. 215. 


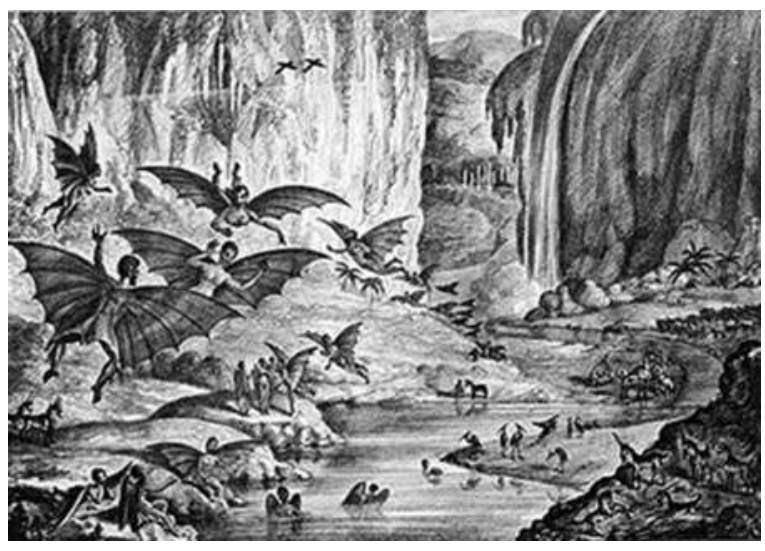

Figure 1. 'Ruby Amphitheater' from the New York Sun (28 August 1835), anon.

monuments described in the passage above indicate not only indigenous culture and intelligence, but also, the author speculates, an awareness of future terrestrial history. Uncertainty as to whether the enflamed globe represents another world's past or Earth's fate not only suggests that different celestial bodies may possess variations of a common history, but also untethers celestial history from a single chronological sequence and problematizes a narrative of human progress: either these lunar beings have the gift of prophecy, or the entire history of human civilization (including our planet's apocalyptic ending) has in some sense already happened.

This article examines the cultural and intellectual interaction between optical technologies and historical concepts in the plurality-of-worlds debate in the nineteenth century. The enhanced powers of the telescope and spectroscope, described by Richard A. Proctor in 1870 as 'light-gatherer' and 'light-sifter' respectively, encouraged claims that Earth did not possess a singular and special status in the history of creation and speculation as to the existence and character of our fellow beings in the universe. ${ }^{4}$ My claim is that in addition to the fanciful speculations of astronomers who imagined beings and worlds beyond the limited capacities of their instruments, there was another stage of these conjectures, which was to imagine the history of other worlds. This imaginative step allowed new reflections on history itself, and the concept of plurality was inflected by, and became an expression of, different historiographical stances during the nineteenth century.

Pluralist speculation was both a marginal branch of astronomy (in relation to the more empirical study of positional astronomy), and a popular one (texts on plurality ran to multiple editions). It also served as a porous field between scientific and wider, metaphysical cultures of enquiry; Thomas De Quincey commented on the nebular debate in 1846 and his response to the alleged discoveries of Lord Rosse's telescope was notable for its departures from scientific caution and his use of fantastical literary

4. Richard A. Proctor, Other Worlds Than Ours, 3rd ed. (London: Longmans, Green, 1872), p. 37 (original emphasis). 
imagery to explore the significance of an astronomical discovery. The mid-century phase of the debate, before spectrum analysis had closed down the nebular controversy, was the period when arguments for and against plurality were tied up with a host of other discussions. These included the composition and dynamics of nebulae, the limits to analogical and inductive reasoning, and the question of how other academic disciplines - geology, biology and even history - might interact with astronomical knowledge. William Whewell (then president of the British Association for the Advancement of Science) and David Brewster argued respectively against and for plurality in two high-circulation and repeatedly reprinted texts: Of the Plurality of Worlds: An Essay (1853) and More Worlds than One: The Creed of the Philosopher and the Hope of the Christian (1854). ${ }^{5}$ My analysis of nebular controversies focusses on the articulation of various disciplinary questions that the imagination of unseen worlds provoked.

The section titled 'Astral projection' will show how, by the 1870s and 1880s, the evidence of spectrum analysis had indicated that other worlds were likely to be composed of similar materials to our own and the conception of other worlds as counterparts of Earth was taken up by astronomers and writers of fiction alike. ${ }^{6}$ The tendency of the pluralist astronomical imagination was to undermine a geocentric view of the universe; also, the recognition of light as historical information, travelling through the universe at a finite speed, made it possible to imagine multiple observers in space, receiving each other's histories as light transmissions. ${ }^{7}$ Astronomers' imaginative self-projections into the cosmos rendered space as an interplanetary and historical web of telescopic gazes. This phase in plurality, in which enhanced optical technologies invigorated astronomical speculation, exemplifies how advances in instrumentation did not necessarily assist the general rise of scientific objectivity that Lorraine Daston and Galison describe. ${ }^{8}$

The final section will examine how the anti-providentialist historiography of Louis Auguste Blanqui's astronomical hypothesisof 1872, as well as the astral figures that appear in Friedrich Nietzsche's second meditation on the use of history, used the concept of plurality to critique the cultural complacency of equating history

5. Whewell's Of the Plurality of Worlds was first published in 1853 and had run to a third edition within a year; Brewster's More Worlds than One appeared in 1854 in response, and was still being republished in a new, illustrated edition in 1876.

6. Camille Flammarion, La Pluralité Des Mondes Habités: Étude Ou L'on Expose Les Conditions D'habitabilité Des Terres Célestes, Discutées Au Point Du Vue de L'astronomie, de La Physiologie et de La Philosophie Naturelle (Paris: Didier, 1869); Camille Flammarion, Lumen (Paris: E. Flammarion, 1887); Edward Everett Hale, 'Hands Off', in Alternative Histories: Eleven Stories of the World as It Might Have Been (New York: Garland, 1986), pp. $1-12$.

7. In 1846 Felix Eberty conceived of space as a total archive of the universal history, all the events of which are still travelling through the cosmos in every direction (Felix Eberty, The Stars and the Earth; or, Thoughts Upon Space, Time, and Eternity (Boston, MA: Crosby, Nichols, 1854), p. 116ff).

8. Lorraine Daston and Peter Galison, Objectivity (New York: Zone Books; distributed by MIT Press, 2007), chap. 3. 
with progress. This article does not wish to argue against the established account of nineteenth-century intellectual history as a process of disciplinary formation which for historical thought involved its transformation from a romantic to a scientific field of study. ${ }^{9}$ It does show, however, that by making light the signature of celestial composition (as spectral analysis affirmed), and of universal history (as the transmission of the past through space), scientific analysis enabled philosophical critiques of human singularity in the cosmos; and these critiques invoked plurality in order to do so. Blanqui's historiographical declaration 'there's no progress!' is, he tells us, 'just a simple conclusion based on spectral analysis and Laplace's cosmogony. ${ }^{10}$ History may have become an increasingly scientific and positivist discipline by the end of the century, as Jann and Dowling have shown; ${ }^{11}$ but the staging of multiple histories among the stars thanks to the information of the telescope and spectroscope allowed critics such as Blanqui and Nietzsche to turn an empirical model of knowledge as steadily additive and accumulative against itself. Plurality served as a proposition that allowed the relations between disciplines to be contested and rearticulated, and was one in which historical concepts were always involved.

\section{Nebulae and history: a 'philosophical romance'}

Thomas Chalmers' influential contributions to the plurality debate included warnings against unbridled cosmic speculation, and the anticipation of a time when optical proof of other worlds would recast plurality from a speculative proposition to proven knowledge. The influence of his A Series of Discourses on the Christian Revelation: Viewed in Connection with the Modern Astronomy (1817) is seen in the rapid republication of his work (nine reprintings and 20,000 copies in 1817 alone) and in the contemporary attention it drew. ${ }^{12}$ The author of a 30-page response in the British Review described Chalmers as 'a fixed star in that firmament of science, which he has taught to shine with the radiance of the Gospel' and Alexander Maxwell published a full-length response to Chalmers in $1817 .{ }^{13}$ Chalmers also established terms for the debate which would be repeatedly referred to in the nineteenth century, for example his distrust of the imaginative leaps that could be occasioned by analogical reasoning,

9. Rosemary Jann, The Art and Science of Victorian History (Columbus: Ohio State University Press, 1985); Thomas William Heyck, The Transformation of Intellectual Life in Victorian England, new ed. (Chicago, IL: Lyceum Books, 1989); Robin Gilmour, The Victorian Period: The Intellectual and Cultural Context, 1830-1890 (London: Longman, 1993).

10. Auguste Blanqui, 'Eternity According to the Stars', trans. by Matthew H. Anderson, CR: The New Centennial Review, 9 (2009), 3-60 (pp. 57, 58).

11. Jann, Art and Science; Linda Dowling, 'Roman Decadence and Victorian Historiography', Victorian Studies, 28 (1985), 579-607.

12. Crowe, Extraterrestrial Life, p. 184.

13. William Roberts, 'Review: A Series of Discourses on the Christian Revelation, Viewed in Connection with the Modern Astronomy', The British Review, and London Critical Journal, 10 (1817), 1-30 (p. 9); Alexander Maxwell, Plurality of Worlds: Or Letters, Notes and Memoranda, Philosophical and Critical (London: A. Maxwell, 1817). 
and his turn to the microscope to counteract the vertiginous cosmic scale apprehended by the telescope. ${ }^{14}$ He also identified the troubling implications of plurality for the Christian belief in God's special care of mankind on Earth, and cited a passage from the Psalms that would be requoted by Whewell, Brewster and Proctor:

When I consider thy heavens, the work of thy fingers, the moon and the stars, which thou hast ordained; What is man, that you art mindful of him? and the son of man, that thou should visitest him ${ }^{15}$

Chalmers' response to this anxiety was not to deny plurality on the basis of scriptural orthodoxy. Instead, his argument was that correct scientific method would counteract unwarranted speculations of the kind modern astronomy was seen to have encouraged. Chalmers referred to the authority of science in order to protect the Christian values of piety and humility, and simultaneously to safeguard the belief that the creator extended a special care to mankind. The object of the questions (on the nature of 'man' and 'the son of man') must, in this context, refer to their contested singularity in the universe.

The Second Discourse, 'The Modesty of True Science', began with praise for Newton's steadfast empiricism by which no theory is accepted without evidence. 'All the sublime truths of modern astronomy lie within the field of actual observation' he wrote, 'and have the firm evidence to rest upon of all that information which is conveyed to us by the avenue of the senses. ${ }^{\prime 6}$ As the title of the discourse implied, science was divided into the true and the false. Newtonian empiricism was championed, and contrasted with that which is not properly science at all, rather a form of conjectural reasoning which sought to make claims about what could not be directly observed. Chalmers castigated thinkers who 'have winged their audacious way into forbidden regions - and ... have crossed that circle by which the field of observation is enclosed - and there have ... debated and dogmatised with all the pride of a most intolerant assurance. ${ }^{\prime}$ Plurality in the nineteenth century stimulated consideration of science's limits and propriety; the rejection here of conjecture derived from analogy would find an echo later when William Whewell's denial of plurality was framed within the wider issue of the proper function of inductive reasoning in the sciences. $^{18}$

Kant, in his Universal Natural History and Theory of the Heavens (1755), exemplifying the approach deplored by Chalmers, inferred that 'most planets are certainly inhabited', adding that 'conjectures, in which analogy and observations agree

14. Psalm 8.3-4, quoted in: Thomas Chalmers, A Series of Discourses on the Christian Revelation: Viewed in Connection with the Modern Astronomy, 8th ed. (Glasgow: John Smith and Son, 1817), p. 53.

15. Chalmers, Series of Discourses, p. 17.

16. Chalmers, Series of Discourses, pp. 71-72.

17. Chalmers, Series of Discourses, p. 72.

18. William Whewell, 'Modern Science-Inductive Philosophy (Review of J.F.W. Herschel's A Preliminary Discourse on the Study of Natural Philosophy)', The Quarterly Review, 45 (1831), 374-407. 
perfectly to support one another, have the same dignity as formal proofs.' ${ }^{19}$ The object of Chalmers' attack was the mode of reasoning by analogy that concluded, from the existence of life on the one planet of which we have empirical knowledge, that the same must be true on others. Later in the century, Richard Proctor would be obliged to defend plurality from the accusation that it relied upon such crude analogies whose argument he summarized: 'The earth is a planet, and Mars is a planet, therefore what we know about the earth may be inferred respecting Mars, no account being taken of the known difference in the conditions of the two planets. ${ }^{20}$ The movement from the known to the unknown produced the invention of worlds, a process that had more in common with literature than with proper scientific enquiry: Chalmers asked his readers to imagine

that one of these philosophers made so extravagant a departure from the sobriety of experimental science as to pass on from the astronomy of the different planets, and to attempt the natural history of their animal and vegetable kingdoms. He might get hold of some vague and general analogies, to throw an air of plausibility around his speculation. He might pass from the botany of the different regions of the globe that we inhabit; and make his loose and confident applications to each of the other planets, according to its distance from the sun, and the inclination of its axis to the plane of its annual revolution; and out of some such slender materials, he may work up an amusing philosophical romance, full of ingenuity, and having, withal, the colour of truth and consistency spread over it. ${ }^{21}$

The type of enquiry he was alarmed by - and characterized as 'romance' (in opposition to 'sobriety') was one which projected the natural history of our own planet onto other celestial bodies by means of analogy. The future capacity of optical technologies to provide empirical evidence of other worlds was one he did not, however, foreclose; he imagined a time when other worlds might become visible: 'Perhaps some large city, the metropolis of a mighty empire, may expand into a visible spot by the powers of some future telescope' - an anticipation to which the Moon Hoax would respond. ${ }^{22}$ The reader was left in a curious position: awed by the wealth of creation, prepared to countenance the existence of other divinely ordained worlds, but prohibited from imagining their topography and indigenous life. Chalmers described celestial speculation as an act of impossible hubris, using a figure that recalled Icarus and foreshadowed Proctor's and Flammarion's celestial spirits: 'He wings his fancy' to a 'hazardous ... region and vainly strives a penetrating vision through the mantle of .. an obscurity. ${ }^{23}$ Chalmers' readers were not always able to follow his proscriptions; the author of a British Review article endorsed the reconciliation of Christian faith with

19. Immanuel Kant, Universal Natural History and Theory of the Heavens, ed. by Stanley L. Jaki (Edinburgh: Scottish Academic Press, 1981), pp. 186, 107.

20. Richard A. Proctor, Our Place Among Infinities. a Series of Essays Contrasting Our Little Abode in Space and Time with the Infinities Around Us (New York: D. Appleton, 1876), pp. $48-49$.

21. Chalmers, Series of Discourses, pp. 72-73.

22. Chalmers, Series of Discourses, p. 32.

23. Chalmers, Series of Discourses, p. 79. 
the telescope, but made hypotheses of his own about the theological implications of other worlds and their histories: 'The Bible intimates that the history of the redemption of our species is known in other parts of the universe, and allows us to conjecture that other worlds may be concerned in the mysterious virtue of the atonement. ${ }^{\text {,24 }}$ In the same passage he even suggested the possibility of 'unfallen worlds'. Chalmers himself speculated that sin 'may have spread its desolation over all the planets of all the systems' - before catching himself and declaring 'here I stop - nor shall I attempt to grope my dark and fatiguing way, by another inch, among such sublime and mysterious secrecies. ${ }^{25} \mathrm{He}$ was apparently susceptible to the same temptations that he cautioned against. ${ }^{26}$

Thomas De Quincey made no attempt to restrain his cosmic theological fancies. In an extraordinary article, 'System of the Heavens as Revealed by Lord Rosse's Telescopes' (1846), he took the nebular controversy as the occasion to interrogate, among other questions, the singularity of our human history in the universe. ${ }^{27}$ J.P. Nichol had cautiously reported Lord Rosse's claim to have solved the nebular debate, and De Quincey responded to the event in dramatic terms, announcing 'a new era for the human intellect' in an essay published by Tait, as Nichol's System of the World had been. $^{28}$ The fanfare De Quincey sounded in response to this scientific discovery reminds us of the significance (and public impact) of the nebular debate, as Jonathan Smith has shown. ${ }^{29}$ The mystery of these indistinct areas of light in the sky concerned the origins of the universe, and preoccupied advocates and deniers of the plurality of worlds in the mid century. The relationship between plurality and nebulae was made explicit by William Whewell who, after David Brewster's vociferous response to his of the Plurality of Worlds, felt obliged to defend himself against Brewster's accusation that he subscribed to the 'nebular hypothesis' (an expression he himself coined in his Bridgewater Treatise of 1833). In the Preface to the third edition of his work he wrote:

That the Nebulae are not in a state of progress towards becoming systems of worlds, is a doctrine prominently asserted and argued for in the following Essay: that the Nebulae are

24. Roberts, 'Review', p. 15.

25. Chalmers, Series of Discourses, pp. 80-81.

26. David Brewster felt no such restraint and constructed an elaborate explanation of the purpose of the other planets of our solar system - to accommodate the souls of all human beings that had lived on earth until the day of judgement. David Brewster, More Worlds Than One: The Creed of the Philosopher and the Hope of the Christian (London: John Murray, 1862), p. 15.

27. The article was a response to the discoveries of Lord Rosse's telescope as reported by John Pringle Nichol, who had published the findings of the telescope in Thoughts on Some Important Points Relating to the System of the World (Edinburgh: W. Tait, 1846). Grevel Lindop reports that Nichol's friendship with De Quincey extended to sheltering him in the newly built Glasgow observatory to hide from his creditors in 1841, in The OpiumEater: A Life of Thomas De Quincey (London: J.M. Dent, 1981), p. 342.

28. Thomas De Quincey, 'System of the Heavens as Revealed by Lord Rosse's Telescopes', Tait's Edinburgh Magazine, 13 (1846), 566-579 (p. 569).

29. Jonathan Smith, 'De Quincey's Revisions to "The System of the Heavens", Victorian Periodicals Review, 26 (1993), 203-212. 
in such a state of progress, is commonly held in conjunction with the assertion of the Plurality of Worlds. ${ }^{30}$

The historical character of these remarks is clear: the repeated phrase, 'state of progress', indicated development, and an understanding of planets' life-cycles as natural-historical phenomena.

We should then expect questions of plurality to attend Lord Rosse's (premature and incorrect) declaration that the debate was over. The largest telescope of its time appeared to have penetrated the Orion Nebula and revealed that its milky, luminous areas could be 'resolved' by his telescope into separate points of light - stars - at tremendous and previously unimagined distances (Figure 2). De Quincey stated that 'the theatre to which he has introduced us, is immeasurably beyond the old one which he found,' ${ }^{31}$ and cast Rosse in the role of an imperative demi-urge 'that says to the rebellious nebulae, - "Submit, and burst into blazing worlds!" that says to the gates of darkness, - "Roll back, ye barriers, and no longer hide from us the infinities of God!" 32 The revelation was curiously qualified however; 'he revealed more by far than he found' De Quincey added in a telling aside that established the space for his own 'discovery'. ${ }^{3}$ When De Quincey contemplated the magnified image of the Orion Nebula, he recognized in it a terrifying figure from historical and literary antiquity:

You see a head thrown back, and raising its face, (or eyes, if eyes it had,) in the very anguish of hatred, to some unknown heavens. What should be its skull wears what might be an Assyrian tiara, only ending behind in a floating train .... Brutalities unspeakable sit upon the upper lip, which is confluent with a snout; for separate nostrils there are none .... One is reminded by the phantom's attitude of a passage, ever memorable in Milton: that passage, I mean, where Death first becomes aware, soon after the original trespass, of his own future empire over man. ${ }^{34}$

The act of resolving a distant nebula, made possible by enhanced telescopic power, here projected the author's reflections backwards in history, first to antiquity then to the literary-mythological: in the nebula he recognized an object of Egyptian statuary from the British Museum, which then gave way to (or 'resolved' as) the figure of Death in Milton's Paradise Lost. The pursuit of the material origin of the universe has been overlaid with another understanding of origin, as John Barrell explains: 'It may be that most primal scene of all, therefore, that De Quincey is figuring in the form of the original act of incest described in Paradise Lost. ${ }^{35}$ We should not overlook the two-way temporality of the scene, however; as well as staging a primal mythological scene, this figure of death anticipated the 'future' catastrophe of man's fall, an anticipation which

30. William Whewell, Of the Plurality of Worlds: An Essay, Also a Dialogue On the Same Subject, 5th ed (London: Parker, 1854), p. 329 (original emphasis).

31. De Quincey, 'System of the Heavens', p. 569 (my emphasis).

32. De Quincey, 'System of the Heavens', p. 570.

33. De Quincey, 'System of the Heavens', p. 569.

34. De Quincey, 'System of the Heavens', p. 571.

35. John Barrell, The Infection of Thomas De Quincey: A Psychopathology of Imperialism (New Haven, CT: Yale University Press, 1991), p. 109. 


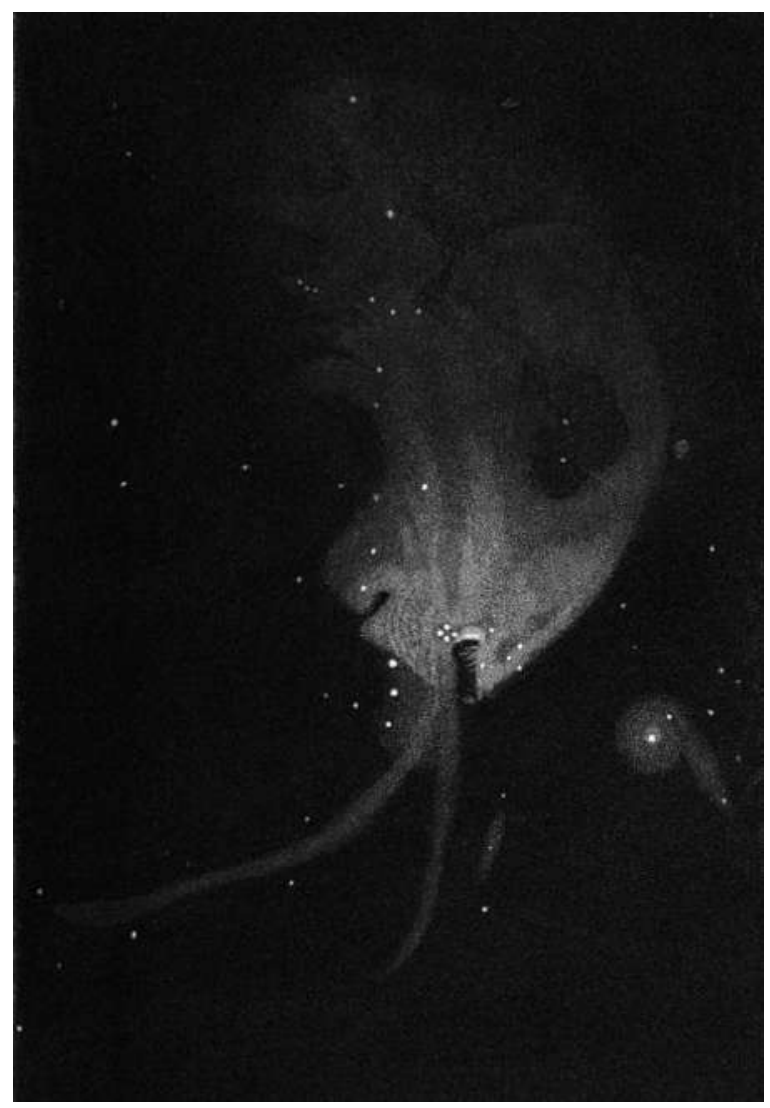

Figure 2. 'Nebula of Orion, figured by Sir J. Herschel' John Pringle Nichol, Thoughts on Some Important Points Relating to the System of the World (Edinburgh; London: John Johnstone, 1848), fig. VIII.

may recall the telescopic revelation of the moon hoax: the depiction of earth's final destruction.

De Quincey's visions did not constitute a direct intervention in the plurality debate. They did, nonetheless, in intense prose, demonstrate the way that optical instruments stripped the gazing self of its groundedness in the realm of the non-visual senses, and facilitated the imagination of other beings in space. In the same essay, he distinguished humanity from the animal kingdom of 'brutes', for whom 'distance is probably not revealed to them except by a presence, viz., by some shadow of their own animality. ${ }^{36}$ The mind projected by a telescope into space was untethered by presence, or proximity, as could be judged by the senses - with disorientation as a consequence. When describing the 'mystery of Space', De Quincey wrote: 'In reality the depths and the heights which are in man, the depths by which he searches, the heights by which he aspires, are but projected and made objective externally in the three dimensions of

36. De Quincey, 'System of the Heavens', p. 570 (original emphasis). 
space which are outside of him. ${ }^{37}$ Space had become a 'theatre' upon which the phantasms of the interior and shadowy realms of the human mind could be staged; and De Quincey's vision was one which, unconstrained by the bodily sensation of 'presence', fleshed out its phantom subject with lips and snout (those bodily faculties which were stripped by optical technologies). For De Quincey, this fabulation of other beings was an effect of optical experience (the monster was upside down), as when he described the apparition (a shadow of the observer) produced by certain atmospheric conditions at the Brocken peak in the Harz Mountains in 'Suspiria de Profundis' (1845). It was a 'reflex of ... inner nature' which 'sometimes swerves out of my orbit, and mixes a little with alien natures. ${ }^{38}$ As with the Orion Nebula, a technologically enhanced mode of seeing multiplied the self, making it an estranged lens-function which produced 'alien natures'.

The consequences of astronomy's excursions into deep space for history were twofold. The first, for De Quincey, was that reflection upon the respective ages and stages of planets' life-cycles made it possible to imagine eternity as a process of historical return, and Earth as 'a Phoenix that is known to have secret processes for rebuilding herself out of her own ashes. ${ }^{39}$ By adopting a model of time as cyclical and endlessly-repeating (a seldom-observed instance of 'eternal return'), De Quincey's vision of the nebula was a manner of expressing fear at a secularization of theological concepts, as Alex Murray makes clear: 'Cast free from [divine revelation] into a process of endless reflection we end up with a horror of the phoenix, at the mercy of the infinite regresses of time and space, destined to repeat ad infinitum the resurrection without revelation. ${ }^{40}$ The second was another troubling transformation of theological cosmology; by replacing the benevolent gaze of the creator with more purposeful observation by other intelligences (which will later in the century be imagined as 'intellects vast and cool and unsympathetic ${ }^{31}$ ), the universe could be notionally populated by other living beings in less or more advanced states of species and civilizational development, and this hypothesis then drew upon astronomy, geology, biology, evolutionary theory in various and contested configurations.

De Quincey's idea of Earth's cyclical history invoked unexpected affinities with geological science. He imagined Earth made unfamiliar by other topographies at previous points in its history: 'Where the south pole now shuts her frozen gates inhospitably against the intrusions of flesh, once were probably accumulated the ribs of empires; man's imperial forehead, woman's roseate lips, gleamed upon ten thousand hills'. We are also invited to think that 'little England' and her 'sweet pastoral rivulets' once contained 'a regal Ganges, that drained some hyperbolical continent. ${ }^{42}$

37. Ibid.

38. Thomas De Quincey, 'Suspiria de Profundis', in Confessions of an English Opium-Eater and Other Writings (London: Penguin Books, 2003), pp. 89-190 (p. 163).

39. De Quincey, 'System of the Heavens', p. 568.

40. Alex Murray, 'Vestiges of the Phoenix: De Quincey, Kant and the Heavens', Victoriographies, 1 (2011), 243-260 (p. 254).

41. H.G. Wells, The War of the Worlds (London: Penguin, 2005), p. 1.

42. De Quincey, 'System of the Heavens', p. 568. 
The imagination of imperial capitals in the polar regions on a previous round of terrestrial history may have been fanciful, but the imagination of England having had dramatic phases of its natural history was less idiosyncratic: Charles Wycliffe Goodwin suggested in 1860 that nature had not always been governable on the British Isles: 'Grand, indeed, was the fauna of the British Islands in these early days. Tigers as large again as the biggest Asiatic species lurked in the ancient thickets; elephants of nearly twice the bulk of the largest individuals that now exist in Africa or Ceylon roamed in herds. ${ }^{43}$ The discoveries of astronomy, like those of geology and biology, provoked historical visions of other civilizations and animal life on the planet Earth, visions that were amenable to projection onto other planets and into deep space. These sources from the mid-nineteenth century are very different, but they both exhibit ways in which biblical and mythological conceptions of the prehistoric past intermingled with an increasingly material understanding of the planet, the universe and their origins.

It was clearly enticing to apply the geological evidence of much earlier ages to ideas of the life of other planets. Richard Proctor captured the relationship of both to plurality when he observed that 'Astronomy and Geology owe much of their charm to the fact that they suggest thoughts of other forms of life than those with which we are familiar'; the spatial removes which astronomy sought to traverse were comparable with the temporal remoteness of previous ages for the geologist; the 'epochs when those monsters throve and multiplied' are almost interchangeable for the supposition of life 'upon other celestial bodies. ${ }^{44}$ The assertion of parallels between disciplines and the extension of evidence from one to another varied from writer to writer. De Quincey, Murray notes, found in the image of the phoenix a means of refuting an idea of successive time that geology was seen to suggest. ${ }^{45}$ Another equivalence between scientific disciplines was drawn by Robert Chambers, whose Vestiges of the Natural History of Creation was published anonymously in 1844, and assumed plurality on the basis of evidence from the disciplines of biology and geology - and proceeded in precisely the direction that Thomas Chalmers had prohibited: 'to pass on from the astronomy of the different planets, and to attempt the natural history of their animal and vegetable kingdoms. ${ }^{46}$ Chambers asserted the affinity between the globule at the molecular level and the nebula at the cosmic. The universal forms, Chambers claimed, were able to produce worlds and life: 'analogy would lead us to conclude that the combinations of the primordial matter, forming our so-called elements, are as universal as to take place everywhere, as are the laws of gravitation and centrifugal force. ${ }^{47}$ M.J.S. Hodge summarizes Chambers' argument as one of completed development: 'Clearly [for Chambers], just as all celestial bodies are more or less perfected and developed nebulae, so all animals and plants are more or less developed

43. Charles Wyclliffe Goodwin, 'Mosaic Cosmogony', in Essays and Reviews: The 1860 Text and Its Reading, ed. by Victor Shea and William Whitla (Charlottesville: University Press of Virginia, 2000), pp. 345-386 (p. 366).

44. Proctor, Other Worlds, p. 1.

45. Murray, 'Vestiges of the Phoenix', p. 248.

46. Chalmers, Series of Discourses, pp. 72-73.

47. Robert Chambers, Vestiges of the Natural History of Creation (London: Routledge, 1890), p. 30. 
globules. ${ }^{48}$ The absence of mammals on the Galapagos Islands, reported in Darwin's Voyage of the Beagle (1845), only reinforced Chambers' idea of the programmatic development of species hierarchies: it appeared to him that life evolved in similar patterns on different parts of Earth, but that some places had not yet reached their time for developing higher forms of life. ${ }^{49}$ This heterogeneous development of species in time and location was taken as a domestic version of how, analogy suggested, they would develop on other planets also.

In Of the Plurality of Worlds (1853), Whewell applied his views on scientific method to the question of plurality in response to the success of Chambers' Vestiges and to refute its conjectures of variant life forms developing on other planets; ${ }^{50}$ his concern was both methodological (asserting the proper and careful mode of inductive reasoning over loose analogical conjectures), and also spiritual: 'if Venus and Mars also have their inhabitants; if Saturn and Jupiter, globes so much larger than the earth, have a proportional amount of population; may not man be neglected or overlooked? Is he worthy to be regarded by the Creator of all? ${ }^{51} \mathrm{He}$ did not reject parallelism between the disciplines of geology and natural history (and their application to plurality), but derived from them an anti-pluralist conclusion. He argued, in the chapter 'The Argument from Geology', that human life, while divinely ordained, only occupied a tiny fraction of Earth's history as a planet, and likewise that life was as rare in the space of the universe as it was in the time of Earth's geological history. The decision to engage one scientific discipline (geology) to police the pluralist inferences apparently encouraged by another (natural history) should also be understood in light of Whewell's extensive writings on the inductive nature of scientific interpretation. Personifying induction in female form, Whewell affirmed that 'she does more than Observation, inasmuch as she not only collects facts, but catches some connexion or relation among them. ${ }^{52}$ Induction might contain a creative process on the part of the observer, but it was not the same as assuming from a single instance (the flora and fauna upon earth) that similar processes of life and evolution (species history) were taking place on other planets.

Evolutionary theory, if applied to other planets, provoked the hypothesis of other species forms, and challenged the special status of Earth that Chalmers declared (at least until visual evidence of other life-forms existed). Whewell resisted these extensions of theory by arguing that space and time contain vast realms of emptiness, to which Earth and its inhabitants were a sacred exception. De Quincey's reaction to the apparent demystification of the nebula and the expansion of space by powerful telescopes may have been singular in the force of its imagery, but it was embedded in

48. M.J.S. Hodge, 'The Universal Gestation of Nature: Chambers' "Vestiges" and "Explanations", Journal of the History of Biology, 5 (1972), 127-151 (p. 142).

49. Hodge, 'Universal Gestation', p. 148.

50. Crowe, Extraterrestrial Life, p. 267; Hodge, 'Universal Gestation', p. 139.

51. Whewell, Plurality of Worlds, p. 25.

52. Whewell, 'Modern Science', p. 379. For an extensive discussion of Whewell's defence of inductive reasoning, see Laura J. Snyder, Reforming Philosophy: A Victorian Debate on Science and Society (Chicago: University of Chicago Press, 2006), chap. 1. 
advances of astronomical instruments, and serves as an example of precisely the same sort of extrapolation which Chalmers and Whewell warned against, and to which professional astronomers were also subject. On seeing a draft of the article, Nichol commented that to characterize the nebula as Memnon (the figure with the Assyrian tiara) and Satan was 'more worthy of one whom the moon has smitten, than of one who gazes calmly upon the stars. ${ }^{53}$ The narrative of increasing scientific objectivity in the nineteenth century is a familiar one, but the diverse participation in the plurality debate showed the recurring tendency of amateurs and scientific popularizers to respond to the lure of such fancies, as I will discuss in the next section. Following Bernard Lightman and others, we should not simply discount these popular reflections of scientific questions, and their absorption into fiction, as inconsequential to 'proper' science or the history of ideas. ${ }^{54}$ Also, the increasingly empirical character of information derived from new technologies such as the spectroscope can be seen to have increased these speculative departures, and allowed for the boundaries between scientific enquiry, historiographical reflection and literary elaborations to remain porous.

\section{Astral projection}

Spectroscopy transformed astronomical knowledge by providing a means for analysing the chemical composition of light-emitting objects. In 1859, Robert Bunsen and Gustav Kirchoff published their first paper announcing the application of spectrum analysis to the telescope; in 1864 William Huggins published his paper on the stellar spectra of fixed stars, providing evidence for the first time that celestial bodies were made up of the same elements known on Earth, and that there seemed to be evidence that some nebulae were gaseous and unresolvable. Huggins, in a lecture delivered to the BAAS in 1866, declared the significance of the new analysis, and at the same time reinvigorated the interpretation of other planets as analogical to ours:

The new branch of astronomical science which spectrum analysis may be said to have founded has for its object to extend the laws of terrestrial physics to the other phenomena of the heavenly bodies, and it rests upon the now established fact that matter of a similar nature common to that of the earth, and subject to laws similar to those which prevail upon the earth, exists throughout the stellar universe. ${ }^{55}$

The debate between the resolvers and anti-resolvers was effectively over and the potentially infinite task of categorizing stars according to their spectra began. Lorraine Daston and Peter Galison find the spectroscope representative of a new model for

53. Smith, 'De Quincey's Revisions', p. 207.

54. Bernard V. Lightman, Victorian Popularizers of Science: Designing Nature for New Audiences (Chicago, IL; University of Chicago Press, 2007); Martin Willis, Vision, Science, and Literature, 1870-1920: Ocular Horizons (London: Pickering \& Chatto, 2011).

55. William Huggins, 'Results of Spectrum Analysis Applied to Heavenly Bodies', in Essays in Astronomy, ed. by Edward Singleton Holden (New York: D. Appleton, 1900), pp. 363-390 (p. 366). 
scientific objectivity that arose in the late-nineteenth century, one which consisted of 'a scientific self equipped with a stern and vigilant conscience, in need not just of external training but also of a fierce self-regulation, ${ }^{56}$ Thomas Chalmers would surely have approved of this sentiment.

The effect of spectroscopy upon the plurality debate was not, however, immediately to kill off speculations regarding the life and species-history of other planets under a new regime of self-regulation. On the contrary, it briefly reinforced the validity of analogical reasoning as a means to hypothesize about the life and nature of other planets which, it could now be claimed, were constituted of similar materials to those on Earth. From around the mid-century onwards, astronomical science and imagination responded to the idea of light as information: both as a signature of material composition to be deciphered by the spectroscope, and as the visual record of events from the past that would continue undiminished across space. ${ }^{57}$ Lynda Nead develops an argument that the enhanced powers of visualization afforded by the telescopic photograph and the spectroscope encouraged the imagination of other, even more powerful capacities for seeing; and that the pursuit of ever more advanced technologies of visualization was connected to an interpretation of planets and stars as 'gigantic projecting devices, throwing beams into outer space that bore entire histories of worlds and civilizations. ${ }^{58}$ My interest is how telescopy and spectroscopy encouraged the imagination of other worlds as counterparts of Earth, and stimulated an intersubjectivity between worlds that was not passive but dynamic and reflexive. Also, the message of spectrum analysis - that the universe was endlessly the same found its corresponding historiographical orientation in the assertion of repetition rather than singularity and divine providence.

Richard Proctor joined the plurality debate in 1870 with Other Worlds Than Ours, which soon ran to multiple reprintings. Proctor had established his credibility as an astronomer with publications on technical and observational matters, but this and his prolific output as editor of the journal Knowledge meant that by the time of his death, 'Proctor had become the most widely read astronomical popularizer in the Englishspeaking world. ${ }^{59}$ The connection for Proctor between spectroscopy and the imagination of other worlds was clear. He described the spectroscope as 'a light-sifter' enabling the astronomer 'to learn the character of the orbs from which ... light proceeds. ${ }^{60}$ The rapidity with which analogical inferences from the spectroscope could move beyond the data of material constitution is clear: 'we see at once, that in all probability the other planets are constituted in the same way', and that 'The imagination suggests immediately the existence of arts and sciences, trades and

56. Daston and Galison, Objectivity, p. 122.

57. The subject is discussed in Lynda Nead, The Haunted Gallery: Painting, Photography, Film C. 1900 (New Haven, Conn: Yale University Press, 2007), chap. 6; James Emmott, 'Parameters of Vibration, Technologies of Capture, and the Layering of Voices and Faces in the Nineteenth Century', Victorian Studies, 53 (2011), 468-478.

58. Nead, Haunted Gallery, p. 203.

59. Lightman, Victorian Popularizers, p. 299.

60. Proctor, Other Worlds, p. 37. 
manufactures, on that distant world' ${ }^{61}$ There was a desire to go beyond the visible evidence and not only to assume the presence of life, but to render alien life-forms as civilizations which may also be contemplating us.

When Proctor imagined a distant observer watching military-historical events unfold on Earth, variant histories became conceivable: 'We can imagine, for example, an observer on Neptune watching the battle of Waterloo from the early dawn until the hour when Napoleon's heart was yet full of hope, and our great captain was watching with ever-growing anxiety, as charge after charge threatened to destroy the squares on whose stedfastness [sic] depended the fate of a continent. ${ }^{62}$ The interplanetary observation of history was a thought exercise that allowed Proctor to imagine that events, even in the past, could maintain the quality of contingency - that they might have been otherwise. This recalls Chambers' idea, to which Chalmers and Whewell were so opposed (before and after the publication of the Vestiges respectively): the contemplation of life developing out of the same materials and principles of formation as on Earth, but in different circumstances and with different results. Tina Young Choi's recent article illustrates how evolutionary hypotheses around the mid-century also produced a tendency towards historical alternatives; how the idea of contingent evolutionary development encouraged the imagination of other worlds: 'To ask the reader to consider the point in branching between two alternatives, to envision that moment of indeterminacy or indecision, even though that point might be in the past, is to invite a reenactment of that divergence. ${ }^{63}$ The return suggested in Proctor to an anticipatory moment, when historical outcomes hung in the balance, was achieved through consideration of the time taken for light to reach remote parts of the universe. ${ }^{64}$

The desire to project oneself into space and onto the surface of another celestial bodywas written about in depth and detail by James Nasmyth and James Carpenter in The Moon Considered as a Planet, a World, and a Satellite (1874). In a section titled 'A Flight of Fancy' they described the feelings of 'a thoughtful telescopist - watching the moon night after night', and wrote that it is 'almost inevitable ... for such an observer to identify himself so far with the object of his scrutiny, as sometimes to become in thought a lunar being. ${ }^{65}$ This was a process that required imaginative completion of the visual data of the earthbound telescopist, who through analogy could confabulate a world whose reality-status was indeterminate:

61. Proctor, Other Worlds, pp. 44, 45.

62. Proctor, Other Worlds, p. 322.

63. Tina Young Choi, 'Natural History's Hypothetical Moments: Narratives of Contingency in Victorian Culture', Victorian Studies, 51 (2009), 275-297 (p. 288).

64. 'Yet, while our Neptunian would thus have traced the progress of the battle from his distant world, the conflict would in reality have been long since decided, the final charge of the British army accomplished, the Imperial Guard destroyed, Napoleon fugitive, and the Prussians, who to the Neptunian would be seen still struggling through muddy roads towards the field of battle, would have been relentlessly pursuing the scattered army of France.' (Proctor, Other Worlds, p. 322)

65. James Nasmyth and James Carpenter, The Moon Considered as a Planet, a World and a Satellite (London: John Murray, 1916), p. 257. 
There is an irresistible tendency in the mind to pass beyond the actually visible, and to fill in with what it knows must exist those accessory features and phenomena that are only hidden from us by distance and by our peculiar point of view. Where the material eye is baffled, the clairvoyance of reason and analogy come to its aid. ${ }^{66}$

The authors attempted to downplay the departure from the observed to the imaginary: these features were 'only hidden from us by distance and our peculiar point of view', and the exercise of 'clairvoyance' was legitimized through its attachment to 'reason and analogy' - a phrasing which recalls, again, the prohibitions of Thomas Chalmers - as does the chapter's title, 'A Flight of Fancy'. They went on to render in image and text (to which Figure 3 and the quotation below refer) the experience of being seated on a lunar crag and witnessing an eclipse of the sun by Earth:

At all parts where these conditions obtain, the lunar eclipse-observer would see the ring of light around the black earth-globe brilliantly crimsoned; at other parts it would have other shades of red and yellow, and the whole effect would be to make the grand earthball, hanging in the lunar sky, like a dark sphere in a circle of glittering gold and rubies. ${ }^{67}$

The observation of sublime aesthetics in space, and of oneself as witness to this alien scenery, could produce a type of anxiety very different from theological uncertainty; it made space lonely. The 'dreary, desolate grandeur' with which Nasmyth and Carpenter invested the lunar landscape was illustrative of a pattern in late nineteenth-century astronomical writing which will now be discussed: of thinking of the cosmos as uncomprehending and comfortless. ${ }^{68}$

Nicholas Camille Flammarion described the imaginative delights stimulated by the light of planets in 1880 in a strikingly similar way to Nasmyth and Carpenter: 'Where is the thoughtful mind that can see without admiration the brilliant Jupiter, accompanied by his four satellites, entering the field of a telescope inundated with its light, or the splendid Saturn moving along surrounded by his mysterious ring, or a double sun scarlet and sapphire, revealing itself in the midst of the infinite night? ${ }^{\prime 69}$ Flammarion would later found the Sociéte Astronomique de France in 1887 and manage its journal; like Proctor, his output was enormous and included both technical and popular works. His lively interest in Spiritism as a branch of science extended his range beyond that of Proctor, however, and his speculations were explored in works on subjects such as the end of the world and the voyages of celestial beings. ${ }^{70}$ In Lumen (1872), a dialogue between two celestial spirits named Lumen and Quarens, Flammarion presented a less celebratory account of the pleasures of astronomy. The reader learned that the soul

66. Nasmyth and Carpenter, Moon Considered, pp. 257-58.

67. Nasmyth and Carpenter, Moon Considered, p. 266.

68. Nasmyth and Carpenter, Moon Considered, p. 274.

69. Camille Flammarion, Popular Astronomy: A General Description of the Heavens, trans. by John Ellard Gore (London: Chatto \& Windus, 1907), p. 676.

70. Spiritism was proposed by Allan Kardec as a more precise term than 'spiritualism', described in 1857 as the study of 'the relation of the material world with spirits, or the beings of the invisible world' (Allan Kardec, Spiritualist Philosophy: The Spirits' Book, trans. by Anna Blackwell (Boston, MA: Colby and Rich, 1875), p. i). 


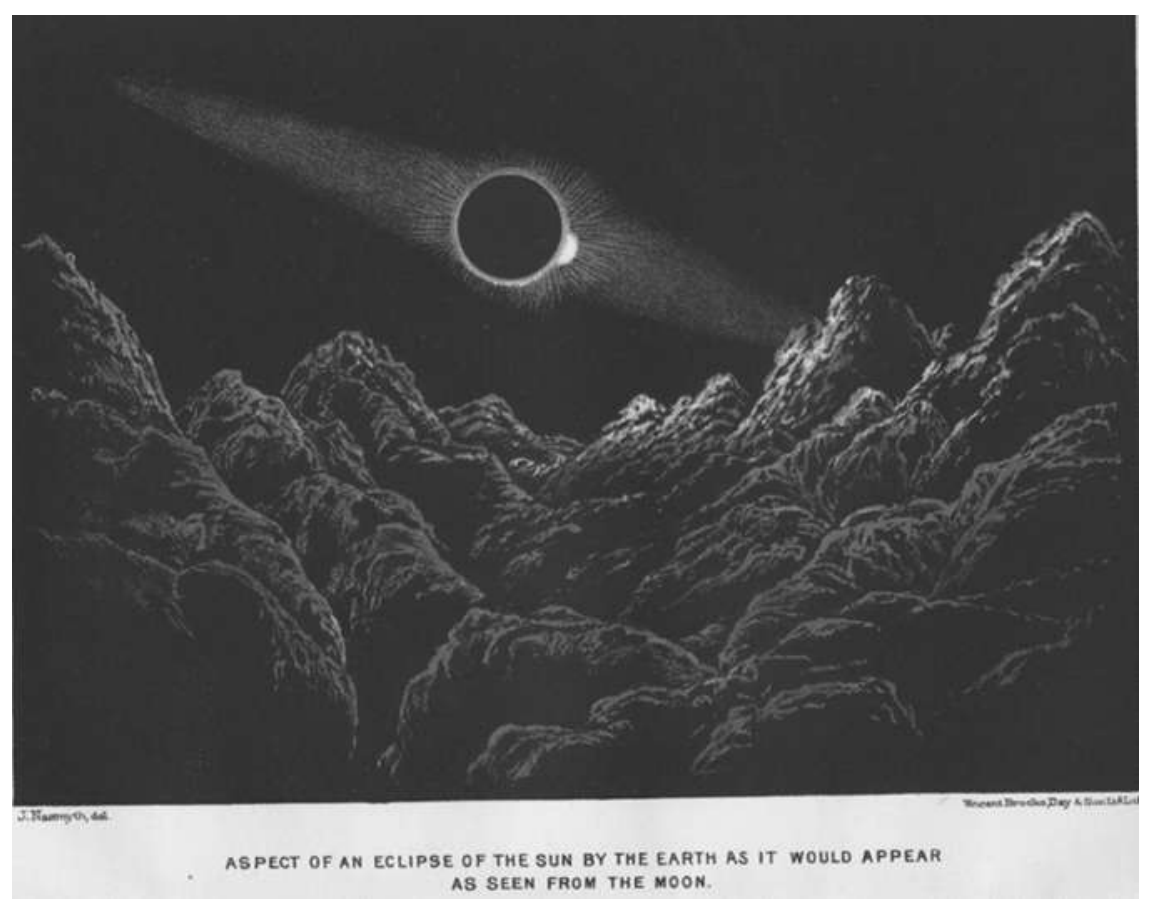

Figure 3. 'Aspect of an Eclipse of the Sun by the Earth', James Nasmyth and James Carpenter. Nasmyth and Carpenter, The Moon, frontispiece.

continued after corporeal death, and that cosmic metempsychosis allowed us to live many lives on different planets before being released as pure spirit; this spiritist claim foregrounded the idea of sameness and repetition rather than difference:

It seemed to me that I had already experienced it .... The spectre of Brocken did not seem new to me. It was that I had already lived in analogous regions on the planet in Virgo. The same life, the same actions, the same circumstances, the same conditions. Analogies, analogies! Almost everything I had seen, done, thought on Earth, I had already seen, done, thought one hundred years before on the earlier world. ${ }^{71}$

The spectre of Brocken (which we have already seen referred to in De Quincey, and which appears also in Goethe's Faust) was a fitting example of experience repeated on multiple worlds, consisting as it did of an image of oneself cast outwards into space when illuminated in the right atmospheric conditions. Also notable in the passage is the suggestion of exhaustion or desolation at the prospect of a repeating series of incarnations with equivalent or similar experiences. The junior spirit and narrator, Quarens, is overwhelmed with the information he receives from Lumen and the book ends on a note of despair at the infinity of time, which is now fully apparent to the initiate. Quarens has the final words of the text as he considers the consequences of never-ending, disembodied existence: 'Eternal life! ... without ... possible ... end!

71. Flammarion, Lumen, p. 121. All quotations from Lumen are my own translation. 
I repeated, searching to comprehend, and feeling my brain melt in its skull ... Ah! ... And I fell as falls a dead man! ${ }^{72}$ The bitter conception of the universe as constituted by sameness (a notion supported by the discoveries of spectroscopy), and a secular, lonely vision of eternity, implied a corresponding conception of our planet's history in an uncomprehending and indifferent universe; Richard Proctor conceded, in a lecture delivered in 1874, that the contemplation of Earth's future history 'is like looking beyond death; for now imagination presents our earth to us as an inert mass, not only lifeless as at the beginning, but no longer possessing that potentiality of life which existed in her substance before life appeared upon her surface. ${ }^{73}$ It was not surprising that astronomy, and plurality in particular, were drawn upon for the figures with which to challenge a conception of history predicated on the technological progress of modernity.

\section{Astral history}

Louis Auguste Blanqui wrote L'Éternité par les astres at the age of 66, having been sentenced to life imprisonment by the Thiers government for political agitation (as he had been by every French government since 1830). A committed plotter, he was seized only days before the insurrection in Paris of March 1871. The Communards are said to have offered an exchange of all their prisoners for Blanqui - an offer which Thiers refused. ${ }^{74} \mathrm{He}$ was released from prison in 1879 and died in 1881 of a stroke after delivering a public speech on the need for an amnesty for the Communards. His absence from the Commune, which he might have led to a different outcome, has to be treated as a formative context of his astronomical hypothesis of the fulfilment of every historical outcome on the infinite worlds contained in the universe. Its thrust, however, was not a claim that the revolution would be fulfilled elsewhere. Instead, his hypothesis was one of material eternity, and the impossibility of believing in the concept of progress in a universe in which, according to science, every historical outcome had already taken place.

None of the existing critical commentaries on L'Éternité par les astres considers it as an intervention in the plurality debate, in which it clearly participated. Blanqui claimed that his conclusions were drawn from Laplace's nebular hypothesis and the discoveries of spectroscopy; he assumed from the evidence of the latter (the universal presence of the same elements) that the number of these elements was finite. This view of equivalent planetary constitution was accompanied by an idea of eternal recurrence. Time was assumed to be infinite, and Blanqui inferred a common interpretation of planetary life-cycles according to which each celestial body underwent a process beginning with birth as a star, followed by cooling and a period of stability, then disintegration until the next collision restarted the process. This went on eternally, in an infinity of time, and was a reiteration of the material eternity of particles that

72. Flammarion, Lumen, p. 225.

73. Richard Anthony Proctor, 'The Past and Future of Our Earth', in Essays in Astronomy, ed. by Edward Singleton Holden (New York: D. Appleton, 1900), pp. 55-82 (p. 79).

74. Alan B. Spitzer, The Revolutionary Theories of Louis Auguste Blanqui, Studies in the Social Sciences/Columbia University (New York: Columbia University Press, 1957), p. 13. Thiers reportedly replied that Blanqui was worth more than an entire battalion. 
Flammarion asserted in Lumen ('an arrangement of material molecules constantly renewing themselves ${ }^{75}$ ). Blanqui's account of planetary formation is notable for its linguistic and imagistic richness:

When, after millions of centuries, one of these immense eddies of stars - having been born and now swirling around, dead together - is able to cover the open regions of space before it, then its borders will collide with other extinguished whirlpools arriving at the encounter. They will then enter into a furious mêlée that goes on for countless years on a battlefield that stretches across billions and billions of leagues. This part of the universe is then little more than a vast atmosphere of flames, unrelentingly furrowed by the cataclysm's lightning bolts, that instantly volatilize both stars and planets. ${ }^{76}$

This account of bodies colliding and initiating an era of chaotic rebirth was of course a description of the nebular formation of planets. It also projected a violent conflict into the heavens, one which was revolutionary in the word's two principal meanings as both cyclical and tumultuous. Jacques Rancière argues that Blanqui's cosmogony was political, for it belonged to his political demand that an equivalent re-imagination of universal processes take place on Earth. ${ }^{77}$ Thus, advances in astronomy enabled a mechanical vision of the heavens that supplanted prior descriptions of celestial order called upon to authorize stable and hierarchical systems of government which privileged stability and fixed relations between constituent elements. Of 'stability and security', in politics or the cosmos, 'the experience of centuries and the universal testimony vigorously reject such hallucinations as these. ${ }^{78}$

Another demystification was theological: eternity and resurrection could now be understood in material terms but with no consolatory power. Earth was in the condition of a stable but moribund planet after its life as a star and prior to its disintegration into its comet phase of interplanetary dust. Our planet was said to have no long-term future, being bound by physical laws to descend eventually into eternal night and barrenness. Humankind would possess a hospitable planet only for long enough to develop a primitive knowledge of the physical nature of the stars. ${ }^{79}$ Given this implacable law of destruction, humans, in an infinite universe, were obliged to accept a view of planetary rebirth: 'Either there is resurrection of stars, or universal death. ${ }^{80}$ This statement wrested the concept of resurrection from a Christian context while maintaining its tropes: dead planets dwell in 'the night's entombment' until 'the moment will come when their flame will again flash up like lightning. ${ }^{81}$ Eternity and resurrection became divorced from a Christian narrative of salvation by being rendered, Blanqui claimed, perfectly intelligible as physical processes by modern

75. Flammarion, Lumen, p. 6.

76. Blanqui, 'Eternity', p. 25.

77. Jacques Rancière, 'Preface', in L'éternité par les astres, Nouv. éd. (Paris: Impressions nouvelles, 2002), pp. 7-26 (p. 10).

78. Blanqui, 'Eternity', p. 32.

79. Blanqui, 'Eternity', p. 10.

80. Blanqui, 'Eternity', p. 33.

81. Blanqui, 'Eternity', p. 24. 
science. Planetary history, knowledge of which was derived from the analysis of light, was made entirely material. Eternity degraded to sempiternity, resurrection to a process of cyclical renewal which was inimical to, not protective of, life and progress. The fate of the earth, like all planets, was to become a 'floating grave. ${ }^{8}$ Blanqui concluded with a cosmology which was felt as repetition both on the planetary level ('The same monotony and the same apathy even in the foreign stars ${ }^{83}$ ) and also for individuals:

What I write at this moment in the dungeons of the Fort du Taureau I will have written for eternity, on a table, with a pen, in my clothes, in circumstances that are completely alike. And so it is, for each. ${ }^{84}$

There was the perception of a disturbing equivalence of our world and others present in Nasmyth and Carpenter's imagination of lunar counterparts, more explicit in Flammarion's notion of repeated experience, and which found its most extreme expression in L'Éternité par les astres. Blanqui's declaration against cultural improvement ('there's no progress!'85) was, crucially, dependent upon the achievements of a technologically advanced culture, one in which academic disciplines were becoming increasingly professionalized and governed by scientific values. Walter Benjamin recognized this when he wrote of Blanqui's hypothesis that: 'taking his data from the mechanistic natural science of bourgeois society, ... it is simultaneously the most terrible indictment of a society that projects this image of the cosmos understood as an image of itself - across the heavens. ${ }^{86}$

The illustration by 'J. J.' Grandville (Figure 4) satirized the same technological selfsatisfaction that was the object of Blanqui's astronomical thesis; it was also included and commented on by Benjamin in The Arcades Project. Grandville's caricature was aimed, surely, at a belief in the universal application of modern engineering, and its capacities to transform all space as it had the cities of the western world. This domesticating and bourgeois perspective on the universality of a phase of culture was the object of Blanqui's critique also, but rather than comic exaggeration, he punctured complacent worldviews through a materialist account of eternity and monotonous repetition. He alerted his readers to the topicality of his thesis at moments in the text: while discussing the composition of stars, for example, he commented that hydrogen and oxygen were the two elements which illuminated the

82. Ibid.

83. Blanqui, 'Eternity', p. 59.

84. Blanqui, 'Eternity', p. 57.

85. Ibid.

86. Walter Benjamin, The Arcades Project, ed. by Rolf Tiedemann, trans. by Howard Eiland and Kevin McLaughlin (Cambridge, MA: Belknap Press, 1999), p. 112. This conjunction of these critics of modernity was perceived by Benjamin, who planned a work on Baudelaire in which a section, to be titled 'The Commodity as Poetic Object', would examine Blanqui and Nietzsche together: Walter Benjamin, Selected Writings, ed. by Michael William Jennings and Howard Eiland, 4 vols. (Cambridge, MA: Belknap Press, 2003), IV, 94n. 


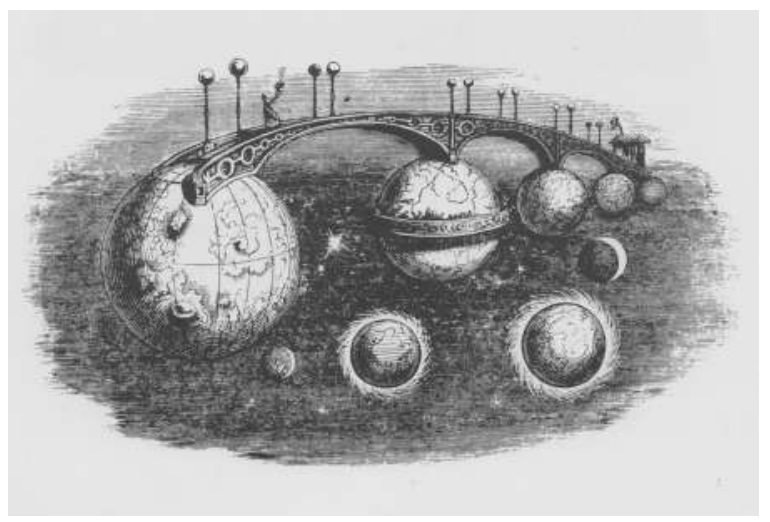

Figure 4. 'Le Pont des planets' ('Interplanetary Bridge'). Engraving by J. J. Grandville, 1844. Laure Garcin, ed., J. J. Grandville: Revolutionnaire et Precurseur de L'art Du Mouvement (Paris: Eric Losfeld, 1970), p. 171.

universe 'as they illuminate the streets of Paris and London' - an equivalence also present in Grandville's portrayal of the globular streetlamps among the stars and planets. ${ }^{87}$ Comets, Blanqui compared with two cultural figures of the nineteenth century: vampires and 'pallid Bohemians. ${ }^{88} \mathrm{He}$ directed his verdict of universal repetition and monotony to 'men of the nineteenth century' and chose as the emblem of material eternity the particularities of fashion: 'The number of our twins is infinite in time and space .... These twins are flesh and bone, in pants and jackets, in crinoline and chignon. These are hardly phantoms, rather the contemporary made eternal. ${ }^{\prime 89}$ Nebulae, fashion and contemporary culture were articulated by Benjamin when he wrote that

$\ldots$ it is precisely in this century, the most parched and imagination-starved, that the collective dream energy of a society has taken refuge with redoubled vehemence in the mute impenetrable nebula of fashion, where the understanding cannot follow. ${ }^{90}$

Nietzsche's use of astral figures to lambast the complacency of modern culture establishes him as an interlocutor of Blanqui - even if their shared interest in eternal recurrence was coincidental. ${ }^{91}$ The historiographical aspect of this modern complacency was clear to Nietzsche as it was to Blanqui. In his first 'Untimely Meditation' ('David Strauss, the Confessor and the Writer'), he identified the dangers that afflicted German culture in the aftermath of military victory over France. These included an automatic

87. Blanqui, 'Eternity', p. 9.

88. Blanqui, 'Eternity', p. 16.

89. Blanqui, 'Eternity', p. 57.

90. Benjamin, Arcades Project, p. 64.

91. Kaufmann claims that Nietzsche's interlocking of human history with the material arrangement of the cosmos is derived from a passage in Heinrich Heine's posthumously published Letzte Gedichte und Gedanken (1869) (Walter Kaufmann, Nietzsche: Philosopher, Psychologist, Antichrist, 3rd ed. (Princeton, NJ: Princeton University Press, 1968), p. 318. 
and unreflecting homage to the 'classics', which led to the self-satisfied view that culture had already produced its greatest treasures and that 'all seeking is at an end.' ${ }^{92}$ The historiographical dimension to his attack on contemporary knowledge appeared in the second meditation. There was not only the well-known characterization of the modern enquirer into history as an 'idler in the garden of knowledge'; ${ }^{93}$ he built a more sustained critique of the 'excess of history' (understood as a 'malady'), which referred to the extension of historical knowledge into all areas of life. ${ }^{94}$ This recalls Foucault's characterization of the century as the one whose 'great obsession' was history, ${ }^{95}$ but for Nietzsche the proliferation of the historical sense took knowledge of the past beyond the mental capacities of individuals: '[history] will not be viewed as a whole at all by that infinitesimal atom, the individual man', and will lead only to 'stupefaction'.96

What then, did Nietzsche mean when he declared that the 'constellation of life and history' had been profoundly altered by the interposition of 'a gleaming and glorious star' - that is 'by science, by the demand that history should be a science'; ${ }^{97}$ and was his choice of the astral figure significant? We should pay attention to the reversal of the relationship between truth and visibility that has been common to the writers discussed so far: notwithstanding the role of the imagination or deliberately fictive accounts, astronomers consistently made observations of the stars the basis for conclusions about the nature of the universe - whether those conclusions were speculative departures from such observations or not. The Moon Hoax pretended to be the descriptions of the enhanced views made possible by a new generation of telescope; Lord Rosse's telescope seemed to have solved the nebular debate, and the data of spectroscopy encouraged Proctor to imagine other counterpart worlds; arguments about intelligent life on Mars hinged on whether Schiaparelli's interpretation of lunar observations was correct. Even Chalmers was prepared to concede other civilizations in the universe if visible evidence could be produced. A conception of history was pushed outwards into space, with conjectural beliefs and anxious reservations attending the development of instruments of seeing.

Nietzsche was thus taking a typically countervailing stance by figuring the 'demand' that history be scientific as a celestial body which had 'interposed' itself and altered the 'constellation' of life and history. A star therefore stood as an obstruction to the perception of constellations - which were themselves the projection of heroicmythic narratives and symbols into the cosmos; those myths affirmed the centrality of

92. Friedrich Wilhelm Nietzsche, 'David Strauss, the Confessor and the Writer', in Untimely Meditations, ed. by Charles Taylor, trans. by R.J. Hollingdale (Cambridge: Cambridge University Press, 1983), pp. 1-56 (p. 10).

93. Friedrich Wilhelm Nietzsche, 'On the Uses and Disadvantages of History for Life', in Untimely Meditations, ed. by Charles Taylor, trans. by R.J. Hollingdale (Cambridge: Cambridge University Press, 1983), pp. 57-125 (p. 59).

94. Nietzsche, 'On the Uses', pp. 64, 120.

95. Michel Foucault, 'Of Other Spaces', in The Visual Culture Reader, 2nd ed. (London: Routledge, 2002), pp. 229-236 (p. 229).

96. Nietzsche, 'On the Uses', p. 101; Nietzsche, 'David Strauss', p. 11 (original emphasis).

97. Nietzsche, 'On the Uses', p. 77 (original emphasis). 
man to the universe, and they were dispelled by the facts of positional astronomy. Man's greatest exploits no longer have the stars as their archive or index (Nietzsche's laments require the masculine), and in precisely the same way history has been transformed so that it no longer serves this purpose either. In a splendidly aphoristic twist, Nietzsche wrote that it was not that history was insufficiently valued, but that the elevation of history as an ever-accumulating, total field of knowledge had impoverished mankind: 'it is possible to value the study of history to such a degree that life becomes stunted and degenerate. ${ }^{98}$ Once extended back towards the earliest origins, history became 'the science of universal becoming. ${ }^{99}$ Heroic events could now be thought of in materialist terms, and no longer confined to single iterations. 'whenever the stars stand in a certain relation to one another a Stoic again joins with an Epicurean to murder Caesar, and when they stand in another relation Columbus will again discover America. ${ }^{100}$ The achievements of science involved another reversion, for the information of astronomical science would introduce an age 'when the astronomers have again become astrologers. ${ }^{101}$

By imagining multiple iterations of human history on Earth, Nietzsche was not stating the existence of a plurality of worlds, but his vision of an endless repetition of history among the infinities of space and time draws him into close affinity with Blanqui's pluralism. It was likewise derived from a model of scientific enquiry which set itself the task of cataloguing the infinite range and history of a material universe; and for Nietzsche this model was then applied to human history on Earth. The astronomers discussed in this article (Whewell, Nasmyth and Carpenter, Proctor) strained their eyes to reach conclusions for or against plurality from the evidence of light transmissions which, if observers had sufficiently enhanced eyes or appropriate instruments, must contain the truths of the universe and its history. Nietzsche saw the 'gleaming and glorious' light of stars and science as one which dazzled and obscured useful knowledge, and despite the wilful perversity of his conclusions his decision to make light central to the debate about the role of man and human history in a material universe was not untimely at all.

\section{Conclusion: hidden things}

How then are those hidden things to be revealed? How, for example, are we to lay hold of the physical basis of light, since, like that of life itself, it lies entirely without the domain of the senses? ${ }^{102}$

John Tyndall asked these questions in a lecture titled 'On the Scientific Use of the Imagination' (1870). He established a delicately balanced position which acknowl-

98. Nietzsche, 'On the Uses', p. 59.

99. Nietzsche, 'On the Uses', p. 77.

100. Nietzsche, 'On the Uses', p. 70.

101. Nietzsche, 'On the Uses', p. 70.

102. John Tyndall, 'On the Scientific Use of the Imagination', in Scientific Use of the Imagination and Other Essays, 3rd ed. (Longmans, Green, 1872), pp. 1-38 (p. 6). 
edged the implications of astronomical science (affirmed by spectrum analysis ${ }^{103}$ ) and the theory of 'Natural Evolution': that as well as the lower and higher animal forms, 'the human mind itself - emotion, intellect, will, and all their phenomena - were once latent in a fiery cloud. ${ }^{104} \mathrm{He}$ still declared, however, that the mystery of creation remained 'untouched': 'For granting the nebula and its potential life, the question, whence came they? would still remain to baffle and bewilder us. ${ }^{105}$ This was a reiteration of a point made by Whewell, also on the nebular theory's account of planetary formation: 'Do we not, far more than ever, require an origin of this origin?' he asked in $1833 .{ }^{106}$ Like Chalmers' earlier mapping of the limits of scientific propriety, this insistence on the resilience of mystery to scientific enquiry posited an ineffable boundary between what could be known by man through observation and scientific theory, and what must remain a source of wonder. By compressing these questions, however, into the examination of light, Tyndall directed us towards the paradox that persisted through the plurality of worlds debate. Light, the condition of visibility, also stimulated the mind to conjecture what remained invisible: the life of the stars and planets which were too far to discern, or the observers of our solar system to whose superhuman vision our history was arriving as light. For light, once it promised the key to Earth's material formation, as well as its history, became a medium for spatially expanded historical reflection in an age in which new sciences were supplanting scriptural accounts of humans' origins in the universe. In Lumen, the junior spirit Quarens asks his mentor to describe the earliest history, when Earth was a terrestrial paradise, and is dismayed to learn that no such period existed, but rather one in which giant monsters fought each other. ${ }^{107}$ The pursuit of light by science was one which posed questions of material historical origins - and led to assertions of unseen monsters and beings. The plurality debate, although impelled by science, is best understood as a battle between two sets of historical imaginaries, and eventually a transition from one to the other. Both of these were 'entirely without the domain of the senses'.

Ben Carver

University of Exeter

bc229@exeter.ac.uk

103. Tyndall, 'Scientific Use', p. 32.

104. Tyndall, 'Scientific Use', p. 35.

105. Tyndall, 'Scientific Use', p. 37.

106. William Whewell, Astronomy and General Physics Considered with Reference To Natural Theology (London: William Pickering, 1833), p. 189.

107. Flammarion, Lumen, p. 68. 